Journal of the Scholarship of Teaching and Learning, Vol. 20, No. 3, December 2020, pp. 20-32. doi: 10.14434/josotl.v20i3.27541

\title{
Reflective Writing and Self-Regulated Learning in Multidisciplinary Flipped Classrooms
}

\author{
Michelle M. Robbins \\ Georgia Gwinnett College \\ mrobbins2@ggc.edu \\ Grace Onodipe \\ Georgia Gwinnett College \\ Alan Marks
Georgia Gwinnett College
}

Abstract: Flipped classes are designed to facilitate self-teaching, self-assessment, and self-regulation (Talbert, 2017). Because flipped classes demand more student responsibility than traditional classes, monitoring their own learning and making adjustments are crucial in helping students perceive this increase as manageable. The current study bypothesized that students in flipped classes would show increases across the semester in their self-regulated learning and that students who engaged in reflective writing tasks (e.g., Nilson, 2013) would show more improvement than those who did not. Data were analyzed from a sample of 332 students enrolled in courses across multiple disciplines. Contrary to expectations, students' motivation and learning strategy scores decreased or remained stable across the semester, except for peer learning, which improved. In general, completing reflective writing tasks seemed to attenuate the decline in motivation scores and actually improve some learning strategy scores. These results suggest the benefit of reflective writing, and future research should examine other mediating/moderating factors, like mindset, in studies involving self-regulated learning and flipped classrooms. Methodological challenges in conducting multidisciplinary SoTL research also are discussed.

Keywords: flipped classes, motivation, learning strategies, learning logs, multidisciplinary research, faculty learning communities

\section{Reflective Writing and Self-Regulated Learning in Multidisciplinary Flipped Classrooms}

In the traditional model of education, students are introduced to new, basic concepts by their professor in class, while more advanced learning of that material occurs on their own after class. This approach has been criticized in part for requiring students to confront more demanding material individually outside the classroom, when they have the least access to instructor support, and for not promoting students' self-regulated learning behaviors as an inherent part of the approach (Talbert, 2017). In contrast, flipped classes require students to gain a basic understanding of new material prior to class time-by completing pre-class work (PCW) - and subsequently in class the instructor facilitates more advanced learning of basic content at a more complex level, typically with active learning and interactive group activities. Students who arrive in class unprepared by not having completed their PCW to understand basic course content are at a disadvantage, unable to master the more complex course material. Thus, competent students learn quickly how to manage their time and study habits with PCW in order to be successful in flipped classes, leaving unresolved the fate of less prepared students. 
Despite the theorized benefits of flipped classrooms, results in the empirical literature have been somewhat inconsistent regarding whether flipped classes are more effective than traditional classrooms regarding academic performance. For example, several studies showed that students in flipped courses performed better academically than those in conventional courses (Van Sickle, 2016; Tune, Sturek, \& Basile, 2013; Mason, Shuman \& Cook, 2013), especially when they were highly motivated (Chen, Wang, \& Chen, 2014). Moreover, retention of information was found to be greater among students taught in a flipped than traditional classroom (Shatto, L'Ecuyer, \& Quinn, 2017). In contrast to such favorable findings for flipped learning and academic achievement, some studies found that students in flipped classrooms performed no better than those in traditional ones (Davies, Dean, \& Ball, 2013; Findlay-Thompson \& Mombourquette, 2014). Moreover, O’Flaherty and Phillips' (2015) qualitative review of the literature on flipped learning suggested that it may be associated with shortterm academic success but not persistent learning. Such conflicting findings highlight the need for further research on the processes by which flipped learning may benefit which students and under what conditions.

Because flipped classes by design facilitate self-teaching, self-assessment, and self-regulation (Talbert, 2017), self-regulated learning may be one mechanism by which students in flipped classes achieve academic success. To that end, flipped classes have been associated with improved selfdirected learning in individual studies (Ihm, Choi, \& Roh, 2017) as well as in a meta-analysis of 12 studies (Liu, et al., 2018). In addition, research has shown that students with higher self-regulation in flipped classrooms have higher self-efficacy and perform better academically than those with lower self-regulation (Sun, Xie, \& Anderman, 2018; Lai \& Hwang, 2016). Moreover, encouraging selfregulated learning behaviors in the classroom has been found to improve student outcomes, specifically for students who are at risk academically (Horowitz, Rabin, \& Brodale, 2013). Selfregulated learning was also found to mediate the link between students' grit (e.g., effort and persistence of interest) and their academic performance (Wolters \& Hussain, 2015). Thus, given the importance of student accountability for their learning in flipped classes, self-discipline and self-regulation are key constructs to study.

Self-regulation requires students to be active participants in their own learning. As Zimmerman (2002) describes it, self-regulation is a process rather than a static skill:

Self-regulation is not a mental ability or an academic performance skill; rather it is the self-directive process by which learners transform their mental abilities into academic skills. Learning is viewed as an activity that students do for themselves in a proactive way rather than as a covert event that happens to them in reaction to teaching. (p. 65)

Further, according to Zimmerman (2002), three primary findings have emerged from prior research on self-regulation. First, self-regulation requires self-awareness, motivation, and the ability to implement behavioral change. For example, self-regulated learners may know they struggle with focusing on reading, be motivated to want to compensate, and implement strategies to improve (e.g., removing distractions, taking notes while reading). Second, self-regulation is a process of setting goals, implementing strategies, monitoring progress, making changes, managing time, and engaging in ongoing self-evaluation (Zimmerman, 2002). Finally, self-regulation requires self-motivation, which is linked to both intrinsic interest and self-efficacy in learning and mastering the material (Zimmerman, 2002). Simply put, being interested in the material and believing you can learn it lead to more studying and practicing of the material, which affords better learning. This sense of self-efficacy has a long history of evidence in the psychology literature through the work of Bandura and others and is consistent with the more recent concept of Dweck's growth mindset concerning academic success (e.g., Yeager \& Dweck, 2012).

Journal of the Scholarship of Teaching and Learning, Vol. 20, No. 3, December 2020. josotl.indiana.edu 
Zimmerman's (2002) summary suggests that self-regulation involves cognitive, motivational, and behavioral components that work in concert, with bidirectional influences. Self-regulated learning requires an honest appraisal of one's learning, habits, and practices and a belief that one can do well (cognitive); a desire and willingness to make changes to be successful (motivational); and an implementation of strategies for improvement (behavioral), with ongoing evaluation and modifications. Students who are strong, self-regulated learners will typically do well coping with the demands of flipped classes, and students who are not already strong, self-regulated learners should become more so through flipped classes. It begs the question, however, as to how a student transforms into a self-regulated learner. Metacognition around one's learning - a seemingly essential part of selfregulation-may be essential for that transformation.

Theorists have emphasized that students' reflecting on their learning improves their learning (e.g., Nilson, 2013). Because flipped classes demand more student responsibility, monitoring their own learning and making adjustments are crucial in helping students perceive this increase as manageable. While some individuals are naturally self-reflective, others may require prompting to be thoughtful about their experiences. In educational domains, learning logs (Weimer, 2013) have been used as a reflective writing strategy to promote knowledge acquisition in wide-ranging disciplines, including STEM (Maharaj \& Banta, 2000), non-STEM (Babcock, 2007), and professional (Grimm, 2015) courses. In one study, social work students described the benefits of reflective writing in terms of their engagement in the course, connection with the instructor, critical thinking skills, enhanced knowledge linking theory and practice, development of professional identity, and improved written communication skills (McGuire, Lay, \& Peters, 2009). Since self-regulation requires active attention to one's own learning, it follows that intentionally requiring students to attend actively to their own learning would enhance self-regulation. It is in that vein that the current study employed learning logs as a reflective writing tool designed to enhance self-regulation. As a metacognitive activity, these "learner" log assignments used specific prompts to promote students' self-awareness and reflection on how they learn. The current study intentionally changed the language from "learning" logs (Weimer, 2013) to "learner" logs, with a subtle intention to link action more with identity, along the lines of higher-order aspects of Bloom's revised taxonomy (Anderson, et al., 2000).

The current study had two primary purposes: (1) to deepen knowledge regarding the potential benefit of intentional self-reflection for self-regulated learning and (2) to do so in the context of flipped classrooms, in an effort to further the empirical body of literature on flipped learning. Specifically, it was hypothesized that (1) students in flipped classrooms would show increased self-regulation over the course of the semester and (2) students assigned regular reflective writing would have greater gains than those not assigned self-reflection tasks. This study capitalized on the existence of a multidisciplinary faculty learning community (FLC) on flipped learning, which afforded a broad, multidisciplinary lens on the above hypotheses.

\section{Method}

\section{Participants}

Participants were undergraduate students at a public, open-access, four-year institution taking courses from nine faculty in various disciplines, representing the schools of business (economics), education, liberal arts (history, psychology), and science and technology (biology, chemistry, mathematics). Overall, data were collected from 402 students (66\% female) across 21 course sections; 332 students completed data at both time points. Participants' mean age was 22.2 years $(S D=5.15)$, and they were $9 \%$ dual-enrolled students, $10 \%$ freshmen, 31\% sophomores, $35 \%$ juniors, and $15 \%$ seniors. The sample was racially/ethnically diverse; specifically, $43 \%$ identified as white, $26 \%$ as black, $14 \%$ as

Journal of the Scholarship of Teaching and Learning, Vol. 20, No. 3, December 2020. josotl.indiana.edu 
mixed/other race/ethnicity, $10 \%$ as Asian, and less than $1 \%$ as Pacific Islander, with $20 \%$ identifying as Latino/Hispanic. Most of the participants were full-time students (74\%), and the majority also worked outside of school (48\% part-time, $25 \%$ full-time). This sample generally represents the diverse student population at our largely commuter-based, majority-minority institution, where nearly $70 \%$ identify as racial/ethnic minorities, $12.5 \%$ report to be nontraditional students (with about $31 \%$ above the age of 23 and nearly $6 \%$ above the age of 35), and about 5\% identify as students dually enrolled in high school and college. Additionally, about $40 \%$ of students at our institution report being the first in their families to attend college.

\section{Procedure}

Participants were recruited from select flipped courses of multidisciplinary faculty who were part of an ongoing FLC on flipped learning. This study was conducted with approval from the institution's IRB. At the beginning of the spring 2018 semester, non-instructor faculty peers from the FLC described the study and obtained informed consent from students in colleagues' courses, to avoid any coercion or obligatory participation. Students were told that their participation was voluntary and would in no way impact their grade in the course and their professors would not know who gave consent until final course grades were submitted. As part of course assignments, students completed a self-regulated learning survey assessing their self-regulated motivation and learning strategies at both the beginning and the end of the semester.

Across disciplines, for instructors teaching two sections of the same flipped course, one section was deemed the "experimental" group, which completed Learner Log assignments as part of regular coursework. The other section, the "control" group, did not complete any assigned reflective writing. Of the 21 course sections, 14 completed learner logs, and seven did not. Learner Log reflective writing prompts were assigned only in the experimental groups as part of regular coursework throughout the semester. The number of prompts varied by instructor, ranging from seven to 15, and prompts were tailored somewhat to meet individual course needs.

\section{Measures}

Self-regulated learning. Students' self-regulated learning was assessed by the Motivated Strategies for Learning Questionnaire (MSLQ; Pintrich, Smith, Garcia, \& McKeachie, 1991), which students completed once at the beginning and once near the end of the semester. The MSLQ consists of 81 items to which respondents rate on a 7-point Likert scale as "not at all true of me" (1) to "very true of me" (7). The 15 total subscales are comprised of six subscales of motivation and nine subscales of learning strategies. The motivation subscales have components focused on: value-Intrinsic Goal Orientation, Extrinsic Goal Orientation, and Task Value; expectancy-Control Beliefs and Self-efficacy for Learning and Performance; and affect-Test Anxiety. A sample Task Value item is "I think I will be able to use what I learn in this course in other courses." The learning strategy subscales have components focused on: cognition and metacognition-Rehearsal, Elaboration, Organization, Critical Thinking, and Metacognitive Selfregulation — and resource management_-Time and Study Environment, Effort Regulation, Peer Learning, and Help Seeking. A sample Peer Learning item is "When studying for this course, I often try to explain the material to a classmate or a friend." Subscale reliability scores generally ranged from adequate $(a=.69$ for Control Beliefs and Peer Learning at time 1 and Effort Regulation at time 2) to high ( $a=.94$ for SelfEfficacy for Learning and Performance at time 2). One exception was the Help Seeking subscale, which was inadequately low at time $1(a=.56)$ and time $2(a=.47)$; given its low reliability, this subscale was excluded from analyses.

Journal of the Scholarship of Teaching and Learning, Vol. 20, No. 3, December 2020. josotl.indiana.edu 
Reflective writing. Students engaged in self-reflective writing about their learning through assigned Learner Logs, which provided specific writing prompts intermittently throughout the semester. A sample prompt typically used early in the semester was:

As you know already, you are in a "flipped" class. A rough way to describe such a class is that the initial learning of course material occurs at home, and classwork allows for deeper, more applied learning. What advantages and disadvantages do you see to having the professor and your fellow students available during the time devoted to the more advanced concepts, problems, and applications? In what ways will the flipped class be both harder and easier than a more traditional course?

As another example, two sets of prompts had the students complete a Study Game Plan sheet prior to their first exam and then reflect on that plan after they received their exam grade, encouraging self-evaluation. Grades were leniently given for thoroughness (i.e., did they answer every part of the prompt) and thoughtfulness (i.e., did their responses reflect some degree of reflection), and in total they were worth a small portion (e.g., 10\%) of students' grades in the various courses.

\section{Results}

A series of mixed model MANOVAs was run to test the first hypothesis, that students in flipped classes would show increased self-regulation across the semester. Results provided mixed support. Across the six motivation subscales, there were significant differences between the scale means $[F(5$, $1655)=266.49, p<.001]$, a significant overall shift in the scales over time $[F(1,331)=10.05, p=$ $.002]$, and a significant two-way interaction between scales and time $[F(5,16555)=5.99, p<.001]$ produced by the mix of significant decreases in extrinsic goal orientation, task value, and self-efficacy for learning and performance scale scores; a non-significant increase in test anxiety; and no significant shifts in the other two scales. Significant mean scale differences over time are shown in Table 1. Across the eight learning strategy subscales, there were significant differences in scale means $[F(7,2317)=$ $110.00, p<.001]$ and a significant two-way interaction between scales and time $[F(7,2317)=15.02$, $p<.001]$ produced by the mix of significant decreases in time and study environment and effort regulation scale scores, a significant increase in peer learning, and no significant shifts in the other five scales. There also was no significant difference in the scales over time $[F(1,331)=0.15$, n.s.]. Figures 1 and 2 show the results for the motivation and learning strategy subscales, respectively. As predicted, peer learning scores significantly increased over time. Contrary to expectations, however, students' other motivation and learning strategy scores remained stable or decreased across the semester.

Journal of the Scholarship of Teaching and Learning, Vol. 20, No. 3, December 2020. josotl.indiana.edu 
Table 1. Descriptive statistics of the Motivated Strategies for Learning Questionnaire (MSLQ) subscales

\begin{tabular}{lcc}
\hline Subscale & (pre) & (post) \\
\hline Motivation & $M(S D)$ & $M(S D)$ \\
$\quad$ Intrinsic Goal Orientation & & \\
Extrinsic Goal Orientation & $5.08(1.00)$ & $5.02(1.17)$ \\
Task Value & $5.77(1.03)$ & $5.59(1.14)^{* * *}$ \\
Control Beliefs & $5.56(1.09)$ & $5.32(1.36)^{* * *}$ \\
Self-Efficacy for Learning and Performance & $5.52(0.95)$ & $5.42(1.13)$ \\
Text Anxiety & $5.65(0.94)$ & $5.42(1.29)^{* * *}$ \\
Learning Strategies & $3.64(1.30)$ & $3.73(1.48)$ \\
Rehearsal & & \\
Elaboration & $5.19(1.13)$ & $5.11(1.17)$ \\
Organization & $5.12(1.06)$ & $5.14(1.13)$ \\
Critical Thinking & $5.06(1.17)$ & $5.08(1.25)$ \\
Metacognitive Self-Regulation & $4.29(1.17)$ & $4.33(1.30)$ \\
Time and Study Environment & $4.95(0.88)$ & $4.89(0.92)$ \\
Effort Regulation & $5.38(0.91)$ & $5.14(1.03)^{* * *}$ \\
Peer Learning & $5.56(1.01)$ & $5.35(1.10)^{* * *}$ \\
\hline
\end{tabular}

Pre vs. post [Full sample $t(331)]^{*} p<.05, * * p<.01, * * * p<.001$

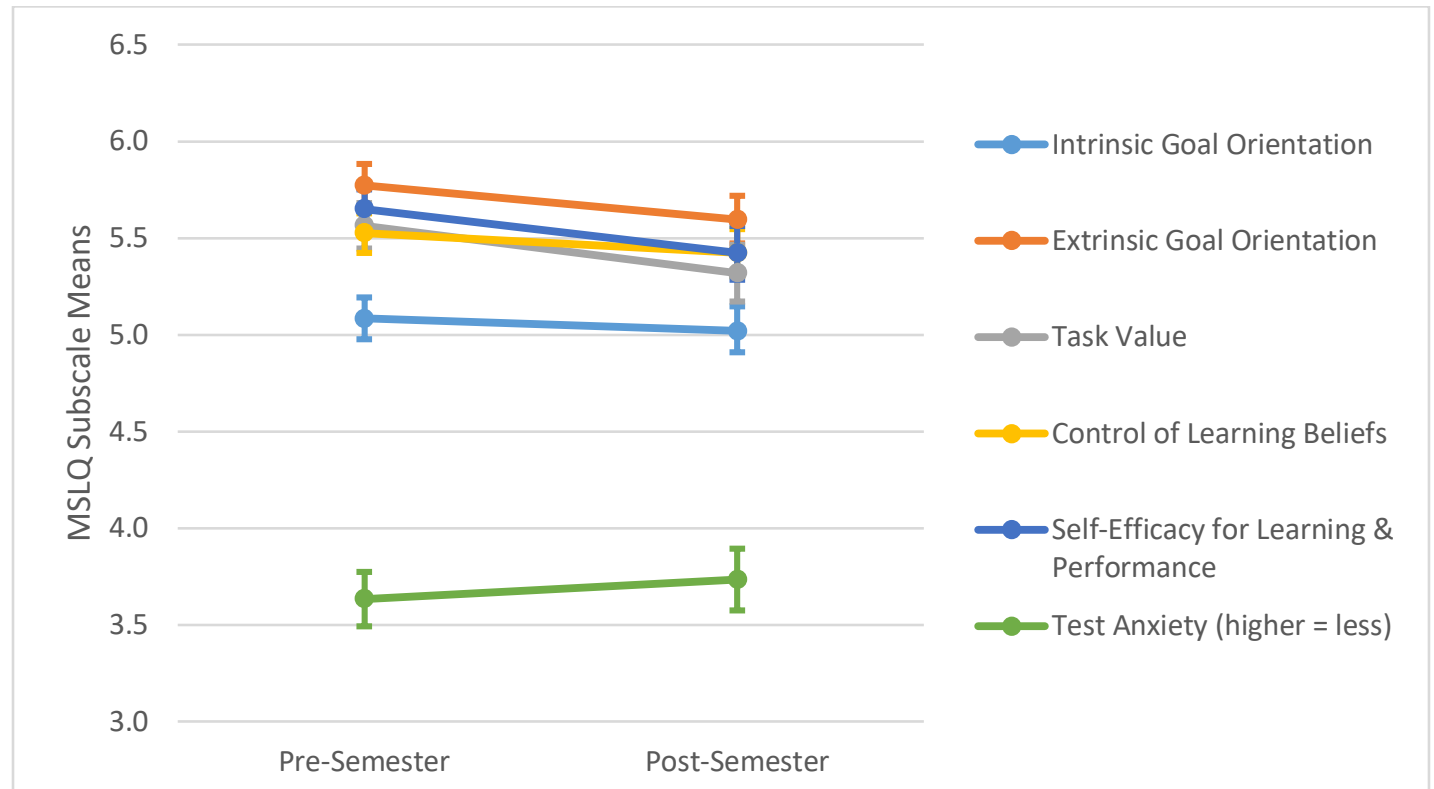

Figure 1. Changes over time on the motivation subscales of the MSLQ. Error bars: 95\% CI 


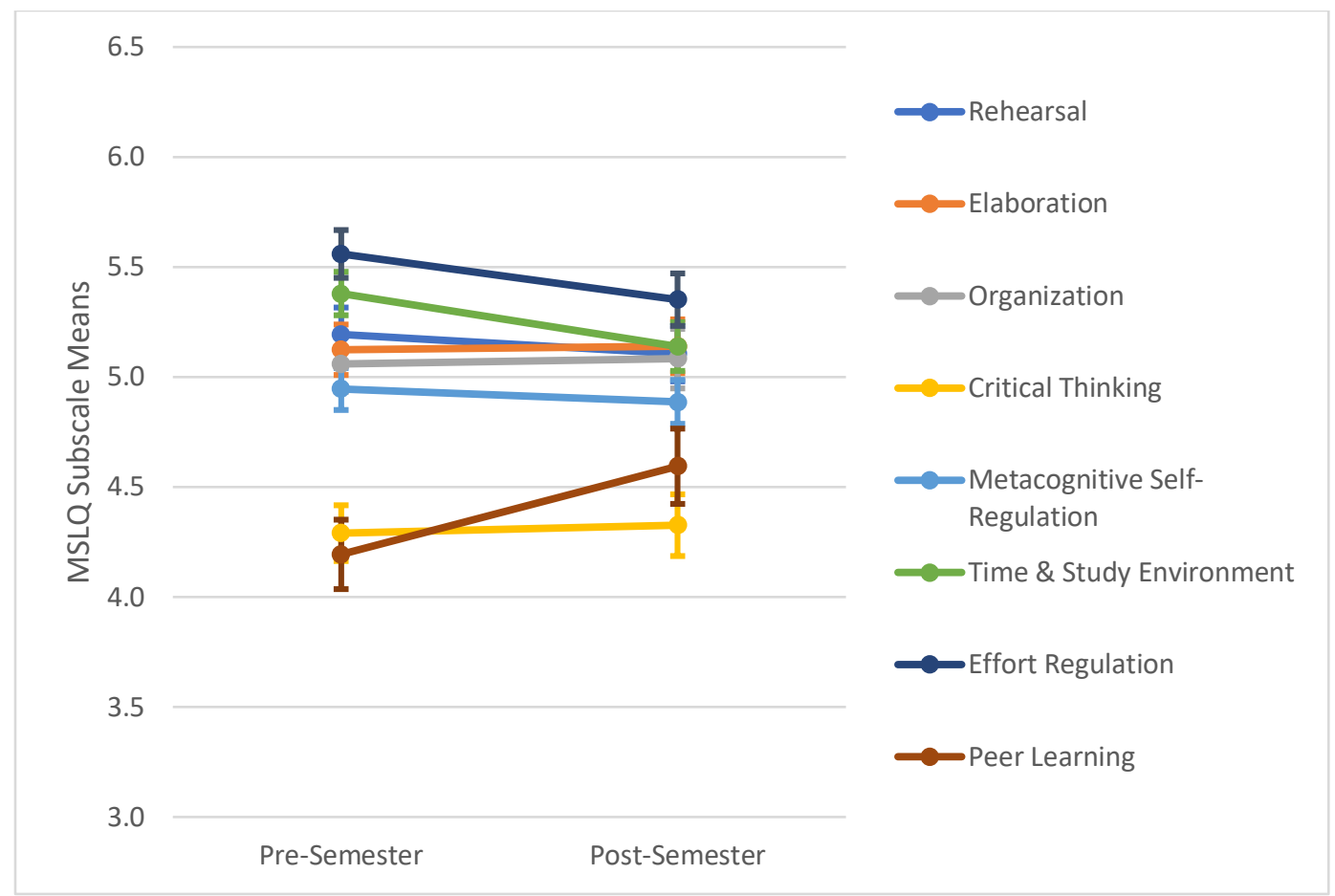

Figure 2. Changes over time on the learning strategy subscales of the MSLQ. Error bars: $95 \%$ CI

The study's second hypothesis - that students in flipped classes who reflectively write about their learning would show improved self-regulation relative to those in flipped classes who do not complete reflective writing-was also examined via a series of mixed model MANOVAs. This hypothesis was partially supported. Significant results for the motivation scales showed main effects for scale $[F(5,1650)=238.34, p=.000]$ and time $[F(1,330)=11.87, p=.001]$, a two-way interaction between scale and time $[F(5,1650)=6.18, p=.000]$, and a three-way interaction between scale, time, and use of learner logs $[F(5,1650)=2.25, p=.047]$. Significant results for the learning strategy scales showed a main effect for scale $[F(7,2310)=100.19, p<.001]$ and two-way interactions between scale and time $[F(7,2310)=10.35, p<.001]$, between time and use of learner logs $[F(1,330)=11.10, p=$ $.001]$, and between scale and use of learner logs $[F(7,2310)=2.48, p=.015]$. Completing learner logs seemed to attenuate the decline in motivation scores and actually improve some learning strategy scores. Specifically, intrinsic goal orientation and control of learning beliefs declined in the control classes but not in the classes that completed the learner logs, as shown in Figure 3. In addition, students who completed the reflective writing logs showed improvement over time on all of the learning strategy subscales except effort regulation and time and study environment, which declined but not as steeply as among students who did not complete the learner logs (see Figure 4). 


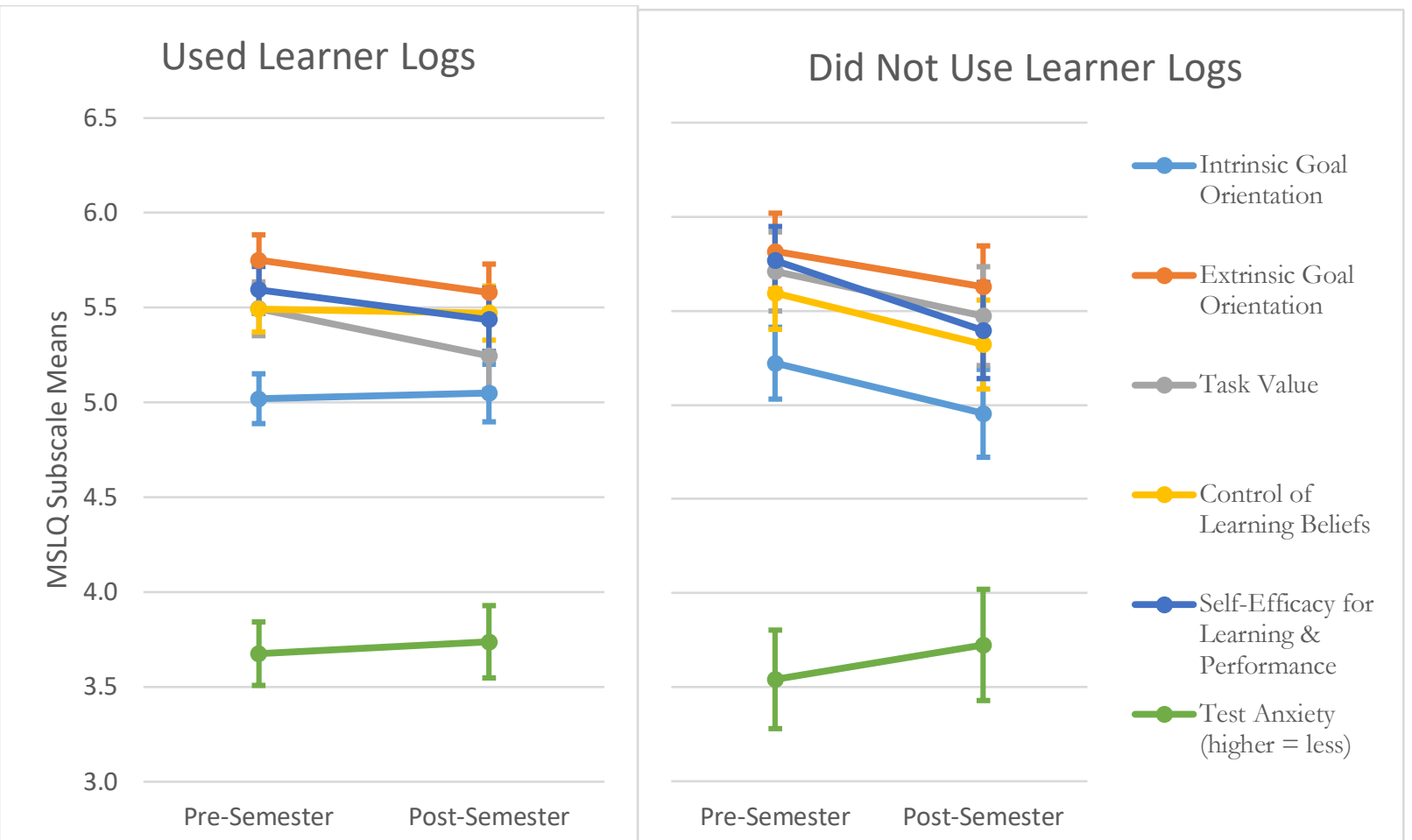

Figure 3. Changes over time on the motivation subscales of the MSLQ with and without completing learner logs. Error bars: 95\% CI

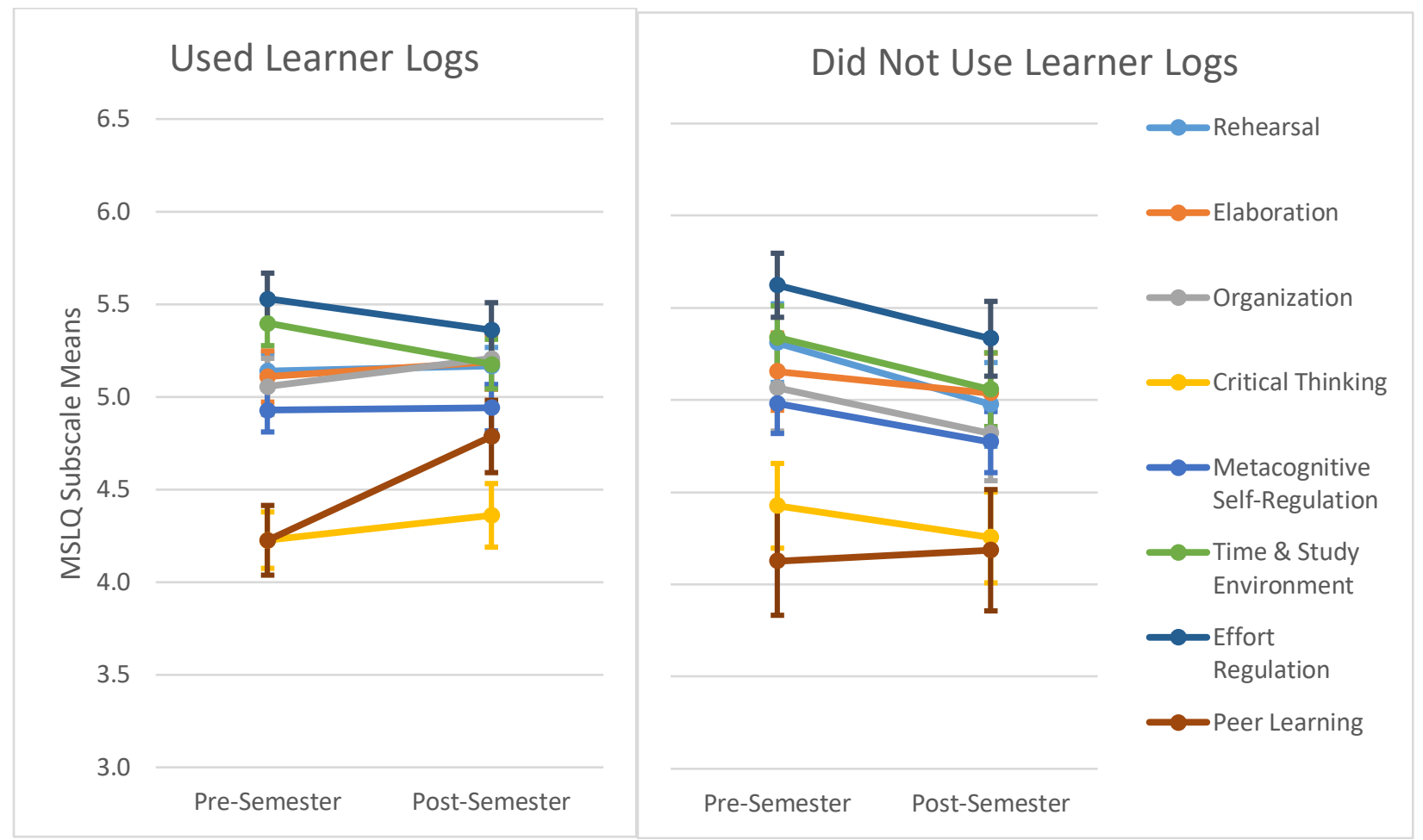

Figure 4. Changes over time on the learning strategy subscales of the MSLQ with and without completing learner logs. Error bars: 95\% CI 


\section{Discussion}

This study adds to the literature on empirical investigations of flipped classrooms by using a large, multidisciplinary sample and examining the potential benefit of reflective writing for self-regulated learning in the context of flipped classes. Contrary to expectations, the current study found that the use of flipped learning in different courses across multiple disciplines seemed to result in a general decrease in self-regulation in terms of motivation and learning strategies. Nonetheless, one important exception to the general decline found in the current study involved peer learning. In addition to fostering autonomy in one's own learning through pre-class work, flipped learning designs also encourage extensive peer interaction during in-class time, with active learning, group-oriented activities. Thus, students learn to engage more with their peers, supporting the significant increase in peer learning found in the current study.

Although self-regulated learning generally decreased across the semester, reflective writing seemed to buffer that decline. Specifically, completing learner logs was associated with stable scores on the motivation scales of intrinsic goal orientation and control beliefs about one's own learning, whereas these scales decreased in classes that did not assign reflective writing. That is, the more students are encouraged to engage in metacognition around their own learning-to actively think about how they learn, their learning goals, and strategies to improve learning-the more they may feel internally motivated and in control of their own learning process and habits (or at least not less internally motivated and not less in control). To that end, plans for future research involving focus groups of students are underway to gain a deeper understanding of students' experiences in flipped classroom designs.

The use of learner logs also mitigated the general decline in learning strategy scores across the semester, such that students who completed reflective writing showed increased use of most of these strategies or stable use, which was an improvement over the decline found in the non-learner log classes. Again, actively thinking about how one learns and ways to improve learning may encourage students to increase their repertoire of strategies to improve their learning. Future research should examine more closely possible mechanisms by which reflective writing might enhance student learning, such as through improved self-efficacy or growth mindset.

Abeysekera and Dawson (2015) argued that although flipped classes may increase students' intrinsic and extrinsic motivation, reduce cognitive load, and enhance student learning, more empirical support is needed for these claims. The findings in this study suggest that, overall, flipped classrooms do not enhance students' self-regulated motivation and learning strategies. Future research should examine what factors may contribute to or attenuate the general decline in motivation in flipped classrooms across the semester. One's prior educational experiences in general or with flipped learning in particular may impact motivation and learning strategies. For example, prior studies have found links between students' self-regulated learning and their perceptions of flipped learning (e.g., Sletten, 2017) as well as their readiness for online work (e.g., Yilmaz, 2017). Moreover, college readiness scores on scales of key cognitive strategies, learning skills and techniques, and content knowledge were higher among first-year college students who had participated in dual enrollment programs compared to those who had not (An \& Taylor, 2015). Thus, a history of dual enrollment may be linked with selfregulated learning in college, which should be tested in future studies, in addition to students' general educational mindset (e.g., Yeager and Dweck, 2012).

The decline in self-regulated learning also may be an artifact of collecting self-report data at the end of the semester, which is often a crunch time for students. The decline thus may represent a secular trend of student fatigue as the end of the semester approaches rather than actual decline in self-regulation. In other words, they may have rushed through or given less thought to completing the MSLQ at time 2, feeling pressured around "one more thing" to have to do, especially given that it was

Journal of the Scholarship of Teaching and Learning, Vol. 20, No. 3, December 2020. josotl.indiana.edu 
not directly related to course material they needed to be studying. If so, that seeming decrease may have been exacerbated during the spring semester, with the end of the school year looming as well. Future research should replicate this study during the fall semester as well as include a control group of non-flipped classrooms.

One limitation in this study was the lack of an additional "control" group of classes that used traditional course design and pedagogy to compare with the flipped classrooms. Interestingly, recent research has provided mixed evidence as to whether flipped learning is associated with increased selfregulation relative to traditional classrooms. For example, Yong, Levy, and Lape (2015) found no such difference in a mathematics course, whereas Van Vliet and colleagues (2015) found significant improvement in self-regulated learning among psychobiology students in flipped versus traditional classrooms initially, but these increases were not maintained. More investigation is needed into when and with whom flipped learning may be more beneficial than traditional learning, and outcomes need to include not only self-reported self-regulated learning but also changes in actual knowledge retention and grades. For example, one recent investigation found that students in a flipped accounting class, relative to a traditional class, had stronger attitudes around experiencing a community of inquiry and learning, fostered by professor and peers, as well as more satisfaction, although these benefits of the flipped classroom were not linked with higher final exam scores (Stover \& Houston, 2019).

Finally, even as there are commonalities across flipped classroom designs, flipped learning is not a manualized approach. To that end, recent researchers have advocated that flipped classes comprise activities designed intentionally using the science of learning (Lawson, Davis, \& Son, 2019). Within the current study, different faculty members implemented flipped learning into their courses in individualized ways best suited to the needs of that particular discipline and course, which is one of the challenges of conducting multidisciplinary SoTL research. Thus, the benefit of a large, multidisciplinary sample also has the potential to obscure individual differences within disciplines. It is possible that the general decline in self-regulated learning we found in the large sample may mask important variations visible only with a closer examination of moderating variables. Prior research has found higher self-regulated learning among students in social and natural science courses who had higher GPAs than those with lower GPAs, but such differences in self-regulated learning by academic achievement was not found among those in humanities courses (Vanderstoep, Pintrich, \& Fagerlin, 1996).

In addition to examining different disciplines, student variables may be key. In a recent study, Lawson, Davis, and Son (2019) found that students in a flipped class with activities specifically designed to help them practice connections, as compared to those in a basic flipped class, performed better on the final exam as well as demonstrated an increase in their growth mindset. Future research should thus examine the influence of different disciplines, flipped design structure and activities, history of dual enrollment, and students' cognitive mindset. Moreover, the current study also had variability in how the learner logs were implemented, including the number of prompts assigned, feedback given, and how grades were earned. A qualitative analysis of students' learner log responses is underway to get a better sense of the quality and depth of students' reflections and how those might be linked with self-regulated learning changes and grades.

\section{Acknowledgements}

This research was conducted as part of a Flipped Learning Faculty Learning Community (FLC). This FLC was awarded grant funding from a combined NSF/internal university-system funded STEM FLC mini-grant for $\$ 3000$, which helped support the pedagogical efforts and travel opportunities for the nine members of the FLC. The first and second authors were co-investigators on this grant. The

Journal of the Scholarship of Teaching and Learning, Vol. 20, No. 3, December 2020. josotl.indiana.edu 
authors wish to thank that funding support as well as the other members of the FLC who played a significant role in this research, without whom this study would not have been possible.

\section{References}

Abeysekera, L., \& Dawson, P. (2015). Motivation and cognitive load in the flipped classroom: Definition, rationale and a call for research. Higher Education Research \& Development, 34, 1-14. https://doi.org/10.1080/07294360.2014.934336

An, B. P., \& Taylor, J. L. (2015). Are dual enrollment students college ready? Evidence from the Wabash National Study of Liberal Arts Education. Education Policy Analysis Archives, 23(58), 1 30. http://dx.doi.org/10.14507/epaa.v23.1781

Anderson L.W., Krathwohl, D.R., Airasian, P.W., Cruikshank, K.A., Mayer, R.E., \& Pintrich, P.R. (2000). A Taxonomy for Learning, Teaching, and Assessing: A Revision of Bloom's Taxonomy of Educational Objectives, Abridged Edition. New York, NY: Pearson.

Babcock, M.J. (2007). Learning logs in introductory literature courses. Teaching in Higher Education, 12(4), 513-523. https://doi.org/10.1080/13562510701415615

Chen, Y., Wang, Y., \& Chen, N. S. (2014). Is FLIP enough? Or should we use the FLIPPED model instead?. Computers \& Education, 79, 16-27. https://doi.org/10.1016/i.compedu.2014.07.004

Davies, R. S., Dean, D. L., \& Ball, N. (2013). Flipping the classroom and instructional technology integration in a college-level information systems spreadsheet course. Educational Technology Research \& Development, 61(4), 563-580. https://doi.org/10.1007/s11423-013-9305-6

Findlay-Thompson, S., \& Mombourquette, P. (2014). Evaluation of a flipped classroom in an undergraduate business course. Business Education \& Accreditation, 6(1), 63-71. https://ssrn.com/abstract $=2331035$

Grimm, S. (2015). Learning logs: incorporating writing-to-learn assignments into accounting courses. Issues in Accounting Education, 30(2), 79-104. https://doi.org/10.2308/iace-50980

Horowitz, G., Rabin, L. A., \& Brodale, D. L. (2013). Improving student performance in organic chemistry: Help seeking behaviors and prior chemistry aptitude. Journal of the Scholarship of Teaching and Learning, 120-133. https://scholarworks.iu.edu/journals/index.php/josotl/article/view/3152

Ihm, J., Choi, H., \& Roh, S. (2017). Flipped-learning course design and evaluation through student self-assessment in a predental science class. Korean Journal of Medical Education, 29(2), 93. https://doi.org/10.3946/kjme.2017.56

Lai, C. L., \& Hwang, G. J. (2016). A self-regulated flipped classroom approach to improving students' learning performance in a mathematics course. Computers \& Education, 100, 126140. https://doi.org/10.1016/i.compedu.2016.05.006

Lawson, A. P., Davis, C. R., \& Son, J. Y. (2019). Not all flipped classes are the same: Using learning science to design flipped classrooms. Journal of the Scholarship of Teaching and Learning, 19(5), 77-104. https://doi.org/10.14434/josotl.v19i5.25856

Liu, Y. Q., Li, Y. F., Lei, M. J., Liu, P. X., Theobald, J., Meng, L. N., Liu, T. T., Zhang, C. M., \& Jin, C. D. (2018). Effectiveness of the flipped classroom on the development of self-directed learning in nursing education: A meta-analysis. Frontiers of Nursing, 5(4), 317-329. https://doi.org/10.1515/fon-2018-0032

Maharaj, S., \& Banta, L. (2000). Using log assignments to foster learning: revisiting writing across the curriculum. Journal of Engineering Education, 89(1), 73-77. https://doi.org/10.1002/j.2168$\underline{9830.2000 . t b 00496 . x}$

Journal of the Scholarship of Teaching and Learning, Vol. 20, No. 3, December 2020. josotl.indiana.edu 
Mason, G. S., Shuman, T. R., \& Cook, K. E. (2013). Comparing the effectiveness of an inverted classroom to a traditional classroom in an upper-division engineering course. IEEE Transactions on Education, 56(4), 430-435. https://doi.org/10.1109/TE.2013.2249066

McGuire, L., Lay, K., \& Peters, J. (2009). Pedagogy of reflective writing in professional education. Journal of the Scholarship of Teaching and Learning, 9(1), 93-107. https://scholarworks.iu.edu/journals/index.php/josotl/article/view/1718/1716

Nilson, L. (2013). Creating self-regulated learners. Sterling, VA: Stylus Publishing.

O'Flaherty, J., \& Phillips, C. (2015). The use of flipped classrooms in higher education: A scoping review. Internet and Higher Education, 25, 85-95. https://doi.org/10.1016/j.iheduc.2015.02.002

Pintrich, P.R., Smith, D.A.F., Garcia, T., \& McKeachie, W.J. (1991). A manual for the use of the Motivated Strategies for Learning Questionnaire (MSLQ). Ann Arbor, MI: National Centre for Research to Improve Postsecondary Teaching and Learning.

Shatto, B., L'Ecuyer, K., \& Quinn, J. (2017). Retention of content utilizing a flipped classroom approach. Nursing Education Perspectives, 38(4), 206-208. https://doi.org/10.1097/01.NEP.0000000000000138

Stover, S., \& Houston, M.A. (2019). Designing flipped-classes to be taught with limited resources: Impact on students' attitudes and learning. Journal of the Scholarship of Teaching and Learning, 19(3), 34-38. https://doi.org/10.14434/josotl.v19i2.23868

Sun, Z., Xie, K., \& Anderman, L. H. (2018). The role of self-regulated learning in students' success in flipped undergraduate math courses. The Internet and Higher Education, 36, 41-53. https://doi.org/10.1016/j.iheduc.2017.09.003

Talbert, R. (2017). Flipped learning: A guide for higher education faculty. Sterling, VA: Stylus Publishing.

Tune, J. D., Sturek, M., \& Basile, D. P. (2013). Flipped classroom model improves graduate student performance in cardiovascular, respiratory, and renal physiology. Advances in Physiology Education, 37, 316-320. https://doi.org/10.1152/advan.00091.2013

Van Sickle, J. R. (2016). Discrepancies between student perception and achievement of learning outcomes in a flipped classroom. Journal of the Scholarship of Teaching and Learning, 16(2), 29-38. https://doi.org/10.14434/josotl.v16i2.19216

Van Vliet, E.A., Winnips, J.C., \& Brouwer, N. (2015). Flipped-class pedagogy enhances student metacognition and collaborative-learning strategies in higher education but effect does not persist. CBE-Life Sciences Education, 14, 1-10. https://doi.org/10.1187/cbe.14-09-0141

Vanderstoep, S. W., Pintrich, P. R., \& Fagerlin, A. (1996). Disciplinary differences in self-regulated learning in college students. Contemporary Educational Psychology, 21, 345-362. https://doi.org/10.1006/ceps.1996.0026

Weimer, M. (2002). Learner-centered teaching: Five key changes to practice. John Wiley \& Sons.

Wolters, C.A., \& Hussain, M. (2015). Investigating grit and its relations with college students' selfregulated learning and academic achievement. Metacognition and Learning, 10, 293-311. https://doi.org/10.1007/s11409-014-9128-9

Yeager, D.S., \& Dweck, C.S. (2012). Mindsets that promote resilience: When students believe that personal characteristics can be developed. Educational Psychologist, 47, 302-314. https://doi.org/10.1080/00461520.2012.722805

Yilmaz, R. (2017). Exploring the role of e-learning readiness on student satisfaction and motivation in flipped classroom. Computers in Human Behavior, 70, 251-260. https://doi.org/10.1016/j.chb.2016.12.085

Yong, D., Levy, R., \& Lape, N. (2015). Why no difference? A controlled flipped classroom study for an introductory differential equations course. PRIMUS, 25, 907-921. https://doi.org/10.1080/10511970.2015.1031307

Journal of the Scholarship of Teaching and Learning, Vol. 20, No. 3, December 2020. josotl.indiana.edu 
Robbins, Onodipe, and Marks

Zimmerman, B.J. (2002). Becoming a self-regulated learner: An overview. Theory Into Practice, 41, 6470. https://doi.org/10.1207/s15430421tip4102 2

Journal of the Scholarship of Teaching and Learning, Vol. 20, No. 3, December 2020. josotl.indiana.edu 